
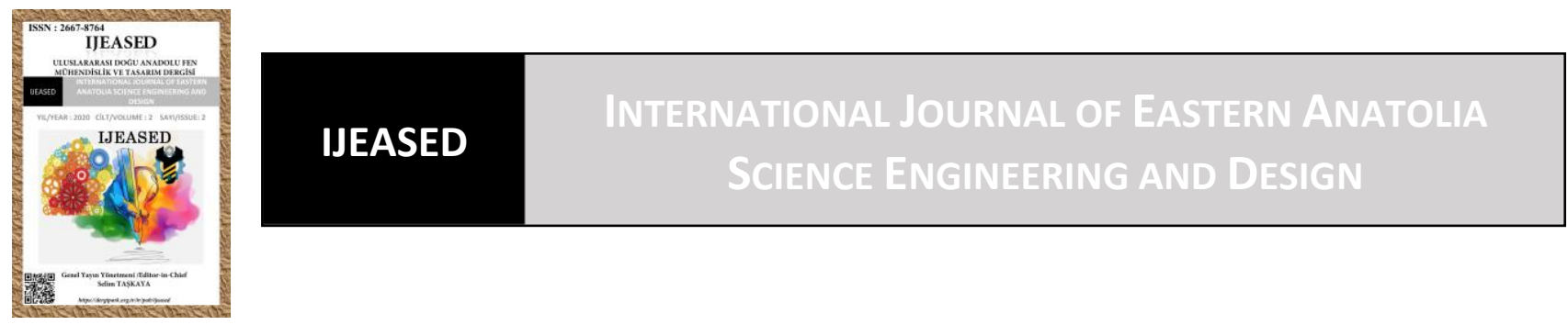

\author{
Uluslararası Doğu Anadolu Fen Mühendislik ve Tasarım Dergisi \\ ISSN: 2667-8764, 2(2), 229-246, 2020 \\ https://dergipark.org.tr/tr/pub/ijeased
}

Araştırma Makalesi / Research Article

Doi: $\underline{10.47898 / \text { ijeased.758097 }}$

\title{
İç Ortamlarda Robot Konumlarının Anlamsal Sınıflandırılması için 2B Lazer Verisi ile PointNet++ Uygulaması
}

\author{
Kaya TURGUT $^{1}$, Burak KALECİ ${ }^{1 *}$
}

${ }^{1}$ Eskişehir Osmangazi Üniversitesi, Elektrik-Elektronik Mühendisliği Bölümü, 26040, Eskişehir, Türkiye.

\begin{tabular}{l|l|l}
\hline \multicolumn{1}{c|}{ Yazar Kimliği / Author ID (ORCID Number) } & \multicolumn{3}{|c}{ Makale Süreci / Article Process } \\
\hline "Sorumlu Yazar / Corresponding author : & Geliş Tarihi / Received Date $:$ & 25.06 .2020 \\
burakaleci@gmail.com & Revizyon Tarihi / Revision Date : & 18.09 .2020 \\
\hline iD https://orcid.org/0000-0003-3345-9339, K. Turgut & Kabul Tarihi / Accepted Date : & 10.10 .2020 \\
iD https://orcid.org/0000-0002-2001-3381, B. Kaleci & Yayım Tarihi / Published Date : & 15.12 .2020 \\
\hline
\end{tabular}

Alıntı /Cite : Turgut, K., Kaleci, B. (2020). İç Ortamlarda Robot Konumlarının Anlamsal Sınıflandırılması için 2B

Lazer Verisi ile PointNet++ Uygulaması, Uluslararası Doğu Anadolu Fen Mühendislik ve Tasarım Dergisi, 2(2), 229246.

\section{Özet}

Son yıllarda, robotlar tarafından yapılması beklenen görevlerin çeşidi ve sayısı her geçen gün artmaktadır. Örneğin, hastane ve okul gibi büyük iç ortamlarda bir nesnenin bir konumdan başka bir konuma taşınması ya da insanlara gitmek istedikleri yere kadar rehberlik edilmesi gibi görevler bunlardan bazılarıdır. Robot konumlarının anlamsal olarak sınıflandırılması, bu görevlerin başarı ile gerçekleştirilmesine katkıda bulunabilir. İç ortamlarda robotun bulunabileceği temel anlamsal sınıflar; oda, koridor, kapı, hol, asansör ve merdiven olarak kabul edilebilir. Geçmiş çalışmalarda, robotun bulunduğu konumun anlamsal sınıfinı tespit etmek amaciyla 2B lazer verisi kümeleme, denetimli ve denetimsiz makine öğrenmesi teknikleri ile kullanılmıştır. Bu çalışmada, geçmiş çalışmalardan farklı olarak nokta tabanlı derin öğrenme mimarisi PointNet++, robot konumlarının oda ya da koridor anlamsal sınıflarından hangisinde olduğunu belirlemek amacıyla kullanılmıştır. Bunu yapabilmek için 2B lazer mesafe ölçerden elde edilen ham mesafe verileri nokta bulutuna dönüştürülmüş ve PointNet++ mimarisine girdi olarak verilmiştir. Ayrıca, mimarinin oda ve koridor sınıflarının karakteristiklerini boyutlardan bağımsız olarak öğrenmesi amacıyla ham veri ölçeklendirilerek veri artırımı (data augmentation) yapılmıştır. Gerçeklenen yöntemin başarısının test edilmesi için farklı boyutlarda oda ve koridorlara sahip Freiburg 79, Freiburg 52, ESOGÜ ve SDR-B binalarından toplanan örneklerin oluşturduğu veri kümeleri kullanılmıştır. Test sonuçları sınıflandırma doğruluğu, duyarlılık, kesinlik ve F1 ölçütü ile değerlendirilmiştir.

Anahtar Kelimeler: Anlamsal konum sınıflandırması, 2B lazer, PointNet++, Gezgin robotlar, İç ortam, Derin öğrenme. 


\title{
An Application of PointNet++ for Semantic Classification of Robot Locations via $2 D$ Laser Data in Indoor Environments
}

\begin{abstract}
In recent years, the variety and number of tasks that expected to perform by robots have been increasing. For example, some of these tasks are to carry an object from a location to another one or to guide people where they desire to reach in large indoor environments such as school and hospital. The semantic classification of the robot locations may contribute to the robots while performing these tasks successfully. In indoor environments, room, corridor, door, hall, elevator, and stair could be considered as the semantic classes that the robot can locate. In previous studies, clustering, supervised, and unsupervised machine learning techniques used with 2D laser data to classify robot locations semantically. In this work, apart from the previous studies, the point-based deep learning architecture PointNet++ was utilized to determine the room or corridor semantic classes. To do that, the raw distance data acquired with the $2 D$ laser range finder was converted to point cloud and the resultant data is used to feed the PointNet++ architecture. Besides, data augmentation was applied to raw point cloud data by means of scaling operation to learn the characteristics of the room and corridor classes regardless of dimensions. The Freiburg 79, Freiburg 52, ESOGU, and SDR-B datasets that include rooms and corridors which have different sizes were used to test the effectiveness of the implemented method. The test results were evaluated with accuracy, recall, precision, and F1 score metrics.
\end{abstract}

Keywords: Semantic place classification, 2D laser, PointNet++, Mobile robots, Indoor, Deep learning.

\section{Giriş}

Son yıllarda, iç ortamlarda robotların bulundukları konumların anlamsal sınıfının belirlenmesi konusu robotik topluluğunda sıklıkla çalışılan konulardan biridir. Bunun temel sebeplerinden biri robotlar tarafından gerçekleştirilmesi beklenen görevlerin karmaşıklığının artmasıdır. Dolayısıyla, robotların bu görevleri yerine getirebilmeleri için algılayıcılarından elde ettikleri ham verileri robot konumlarının anlamsal sınıfı gibi üst seviye bilgiye dönüştürmeleri gerekmektedir. İç ortamlarda robotlar kendilerine verilen görevleri yerine getirirken zamanlarının çok büyük bir kısmını oda ya da koridor anlamsal sınıflarına ait olan konumlarda geçirirler. Şekil 1'de Eskişehir Osmangazi Üniversitesi Elektrik-Elektronik Mühendisliği Laboratuvar binası için robotların sıklıkla bulunduğu oda ve koridor anlamsal sınıfları sırasıyla mavi ve kırmızı renklerle gösterilmiştir.

Anlamsal konum sınıflandırma problemi robotun algılayıcıları ile elde ettiği ham verileri kullanarak bulunduğu konumun anlamsal sınıfina karar vermesi olarak tanımlanabilir (Mozos, 2010). Mozos ve ark. (2005), 2B lazer verilerini kullanarak bu problemin çözümüne yönelik ilk çalışmalardan birini yapmışlardır. Yazarlar, AdaBoost denetimli makine öğrenmesi yöntemine girdi olarak vermek amacıyla lazer mesafe verilerinden basit geometrik özellikler çıkarmışlardır. Bu özellikleri, ham lazer ışınlardan çıkartılan Küme B ve lazer taramasının oluşturduğu çokgenden çıkarılan Küme P olarak iki sınıfa ayırmışlardır. Önerdikleri yöntemi test etmek amacıyla Freiburg 79 veri kümesini oluşturmuş ve kullanmışlardır. Mozos ve Burgard (2006) önerdikleri çalışmada, AdaBoost ile elde ettikleri sonuçları Olasılıksal Gevşetme Etiketlemesi (Probabilistic Relaxation 
Labeling) yöntemi ile düzgünleştirmişlerdir. Yazarlar, Freiburg 79 veri kümesinin yanı sıra Freiburg 52 veri kümesini oluşturmuş ve her iki veri kümesini önerilen yöntemin başarısını gözlemlemek amacıyla kullanmışlardır. Buna ek olarak, önerdikleri yöntemin genelleştirme kabiliyetini ölçmek için SDR-B veri kümesi ile testler gerçekleştirmişlerdir. Freiburg 79 ve Freiburg 52 veri kümeleri ile Mozos ve ark. (2005) önerdiği özellikleri kullanan başka çalışmalar da mevcuttur. Bunlardan birinde Soares ve Araújo (2014) bu özellikleri AdaBoost denetimli makine öğrenmesi yönteminin diğer varyasyonları olan Gentle AdaBoost, Modest AdaBoost ve Generalized AdaBoost yöntemlerini karşılaştırmak amacıyla kullanmışlardır. Premebida ve ark. (2015) ise Destek Vektör Makineleri (SVM - Support Vector Machine) denetimli makine öğrenmesi yöntemi ile bu özellikleri kullanarak iki sınıflandırıcı elde etmişlerdir. Daha sonra bu sınıflandırıcıları ağırlıklandırılmış Bayes Karışım Modeli (Bayesian Mixture Model) ile birleştirmişlerdir. Shi ve ark. (2010) ise B ve P kümelerinden seçtikleri 150 özelliği analiz etmek amacıyla Hesaplamalı Lojistik Regresyon (Computational Logistic Regression) kullanmışlardır. Böylece oda ve koridor sınıflarını verimli bir şekilde ayırt edebilmek için 3 adet baskın özellik belirlemişlerdir. Sousa ve ark. (2007) yaptıkları çalışmada, B ve P kümelerinde yer alan özellikleri SVM ile kullanarak robotun bulunduğu konumları oda ve koridor olarak sınıflandırmışlardır.

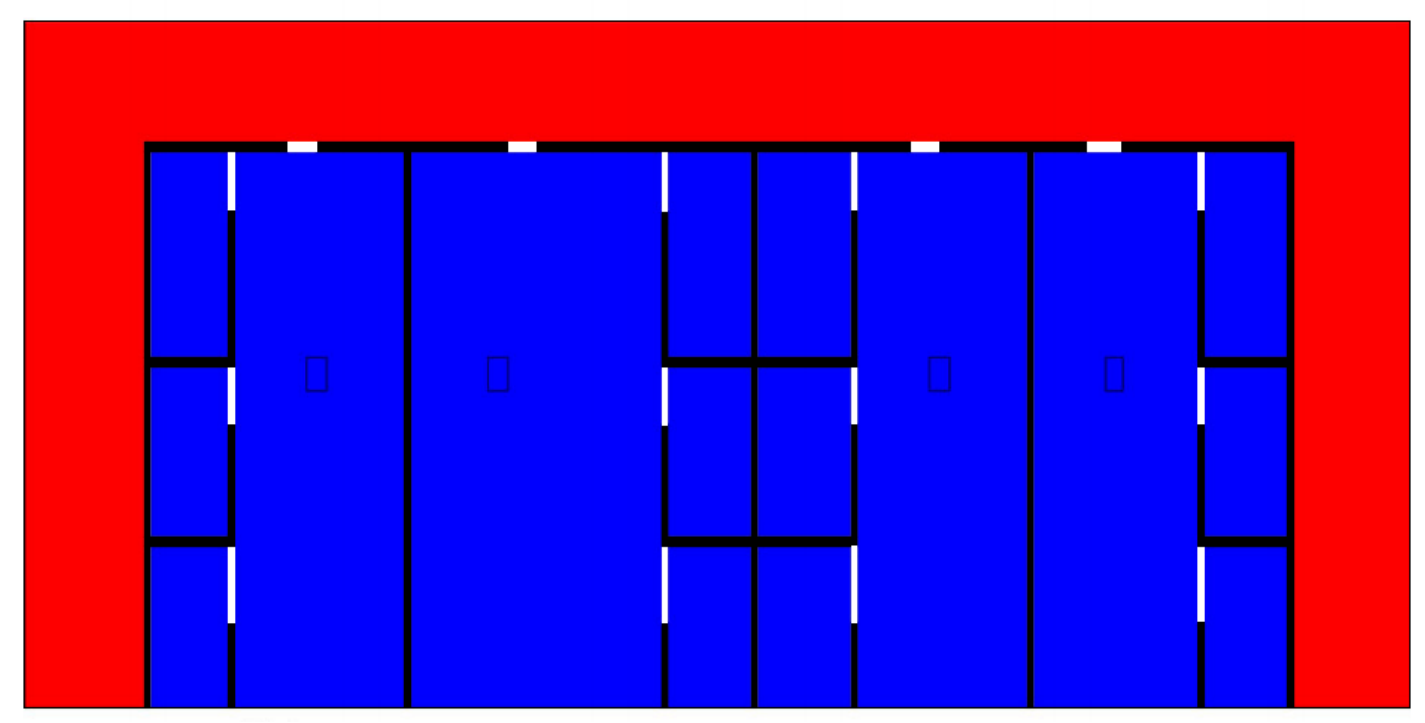

Şekil 1. Eskişehir Osmangazi Üniversitesi Elektrik-Elektronik Mühendisliği Laboratuvar binası için robotların bulunabileceği anlamsal sinıflar.

Küme B ve Küme P özelliklerini kullanan çalışmaların yanı sıra kümeleme ve çizge yöntemlerini kullanarak robot konumlarının anlamsal sınıflarını belirlemeye çalışan yöntemler de 
mevcuttur. Bu çalışmalardan birinde Shi ve Kodagoda (2013) önerdikleri yarı denetimli yöntemde, Genelleştirilmiş Voronoi Çizgesi (Generalized Voronoi Graph), SVM ve Şartlı Rastsal Alan (Conditional Random Field) yöntemlerini kullanarak Freiburg 79 veri kümesinde yer alan koridor sınıfı ile boyutları farklı 2 oda sınıfını belirlemeye çalışmışlardır. Kaleci ve ark. (2020) ise Kortalama, Fuzzy-C ortalama ve SONN (Self-Organizing Neural Network) kümeleme yöntemlerini Freiburg 79 veri kümesinde eğitmiş ve küme merkezlerini elde etmişlerdir. Yöntemlerinin genelleştirme kabiliyetini test etmek amacıyla elde edilen küme merkezlerini kullanarak Freiburg 52 ve ESOGÜ ortamlarında testler yapmışlardır.

Son yıllarda derin öğrenme yöntemlerinde önemli gelişmeler yaşanması ile birlikte bu yöntemler robot konumlarının anlamsal sınıflarının belirlenmesinde de kullanılmaya başlanmıştır. Liao ve ark. (2017) yaptıkları çalışmada Shi ve Kodagoda'nın (2013) önerdikleri çizge tabanlı yapıyı Düzenlenmiş Derin Sinir Ağı (Regularized Deep Artchitecture) ile geniş̧letmişlerdir. Farklı bakış açılarından elde edilen çevresel bilgiler Voronoi Çizgeleri ile temsil edildikten sonra çok katmanlı topolojik yapı çıkarılmıştır. Topolojik yapının her biri için tam bağlantılı katmanlar kullanılarak elde edilen sınıflandırma sonuçları, güvenilirlik karar ağacı ile değerlendirilmiştir. Goeddel ve Olson (2016), imge tabanlı verilerde nesne sınıflandırmak için sıklıkla kullanılan ve başarılı sonuçlar alınan Evrişimsel Sinir Ağını (CNN - Convolutional Neural Network) kullanarak lazer ölçümlerini sınıflandırmışlardır. İlk olarak, lazer ölçümleri doluluk ızgarasına çevrilmiş ve bu 1zgara gri ölçekli imge olarak kabul edilmiştir. CNN katmanları ile imgelerden özellikler çıkarıldıktan sonra sınıflandırma yapılmıştır. Nikdel ve Vaughan (2019) CNN tabanlı yaptıkları çalışmada, SLAM (Simultaneous Localization and Mapping) Gmap verisi ve lazer verisini kullanarak robotun bir anlamsal sınıfta bulunma olasılığını elde etmişlerdir.

Derin öğrenme tekniklerinin ve 3B veri kümelerinin artması ile nokta bulutu sınıflandırma problemi üzerine çalışmalar her geçen gün artmaktadır. Guo ve ark. (2019) yaptıkları derleme çalışmasında, 3B şekil sınıflandırma, 3B nesne algılama ve takip ve 3B bölütleme problemleri üzerine yapılan derin öğrenme çalışmalarına yer vermişlerdir. Nokta bulutunun düzensiz yapısı, sıralamadan ve dönüşümden bağımsız olmasından dolayı CNN gibi derin öğrenme yaklaşımları bu veriye doğrudan uygulanamamaktadır. Bu yaklaşımların kullanılabilmesi için nokta bulutu verisi imge tabanlı (Su ve ark., 2015) ya da voksel tabanlı (Maturan ve Scherer, 2015) düzenli yapılara dönüştürülmüştür. Ancak, bu dönüşümler veri kayıplarına neden olmakta ve hesaplama maliyetini artırmaktadır. Nokta tabanlı ilk çalışma olan PointNet (Qi ve ark., 2016) mimarisinin tanıtılmasıyla birlikte bu alanda çalışmalar hız kazanmıştır. PointNet mimarisi nokta bulutundaki her nokta için 
ağırlıkları paylaştırılmış tam bağlantılı katmanlar kullanılarak özellikler çıkarmaktadır. PointNet, her noktayı bağımsız ve bireysel olarak değerlendirdiği için noktalar arasındaki ilişkileri öğrenememektedir. PointNet++ mimarisi, noktalar arasındaki ilişkiyi tanımlayan yerel bilgileri elde etmek için PointNet'i genişleterek oluşturulmuştur (Qi ve ark., 2017). Bu mimaride, yerel bölgeler belirlendikten sonra bu bölgelerin yerel özellikleri PointNet ile çıkarılmaktadır.

$\mathrm{Bu}$ çalışmada, nokta tabanlı derin öğrenme mimarisi PointNet++, robot konumlarının oda veya koridor anlamsal sınıflarından hangisinde olduğunu belirlenmek amacıyla kullanılmıştır. Bu çalışmanın temel amacı, son yıllarda hızla gelişen ve nokta bulutu verileri ile başarılı sonuçlar üreten derin öğrenme mimarilerinin 2B lazer verileri ile kullanılma potansiyelini gözlemlemektir. $\mathrm{Bu}$ potansiyel, 2B lazer verileri ile çözüm aranan farklı robotik problemlerinde de nokta tabanlı derin öğrenme mimarilerinin kullanılmasına ilham kaynağı olabilir. Böylelikle, kümeleme, çizge, denetimli ve denetimsiz makine öğrenme teknikleri ile bir sınıra dayanmış olan çözümler, derin öğrenme mimarileri ile bu sınırı aşabilir. PointNet++ mimarisini kullanabilmek için 2B ham lazer mesafe ölçümleri nokta bulutuna dönüştürülüp mimariye girdi olarak verilmiştir. Ayrıca, gerçeklenen yöntemin oda ya da koridor anlamsal sınıflarını belirlerken sadece lazer ölçümünün büyüklüğünü öğrenmesini engellemek ve bu sınıfların genel karakteristiklerini anlamasını sağlamak amacıyla veri artırımı işlemi gerçekleştirilmiştir. Bunun için Freiburg 79 eğitim verisi farklı değerler ile ölçeklendirilerek çeşitlendirilmiştir. PointNet++ mimarisi ham ve artırılmış veri için ayrı ayrı eğitilmiş ve her bir veri kümesi için bir model elde edilmiştir. Freiburg 79, Freiburg 52, ESOGÜ ve SDR-B veri kümelerinde bulunan farklı boyutlardaki oda ve koridorlardan elde edilen lazer ölçümleri eğitilen modellerin başarısını değerlendirmek için kullanılmıştır.

\section{Gerçeklenen Yöntem}

İç ortamlarda robotun sıklıkla bulunduğu oda ve koridor konumlarına ait Freiburg 79 veri kümesinden alınan lazer taramaları için örnekler Şekil 2'de verilmektedir. Ham mesafe ölçümleri ile oluşan bu taramalar incelendiğinde anlamsal sınıfların ayırt edici özelliklerinin bulunduğu görülmektedir. Örneğin, oda konuma ait lazer taramaları (Şekil 2(a)) genellikle izotropik yapıda iken koridor konumuna ait olanlar (Şekil 2(b)) uzayan ve genişleyen karakteristiğe sahiptir. Sonuç olarak, ham mesafe ölçümlerinin nokta ile temsil edilmesi ve bu noktalara ait koordinatların özellik olarak kullanılması oda ve koridor sınıflarının karakteristiğini koruyacak ve derin öğrenme mimarileri için anlamlı bilgiler taşıyacaktır. Nokta bulutu, her noktanın $\left(\mathrm{P}_{\mathrm{i}}\right), \mathrm{x}, \mathrm{y}$ ve z koordinatlarından oluştuğu 3B noktalar kümesi $\left\{\mathrm{P}_{\mathrm{i}} \mid i=1,2, \ldots, N\right\}$ olarak tanımlanmakta ve $N$ 
nokta bulutunda yer alan nokta sayısını temsil etmektedir. Bu kapsamda, her bir lazer ölçümüne ait mesafe değeri x ve y koordinatlarına dönüştürülerek 2B uzayda temsil edilmiştir. Ayrıca, sabit bir değere sahip z $(\mathrm{z}=0.3)$ koordinatı eklenerek 3B uzayda bir düzlem oluşturulmuş ve nokta bulutu elde edilmiştir. Her bir nokta bulutu 360 adet nokta içermektedir. Lazer taramalarının nokta bulutuna dönüştürülmüş formu oda ve koridor konumları için sırasıyla Şekil 2(c) ve Şekil 2(d)' de verilmektedir.

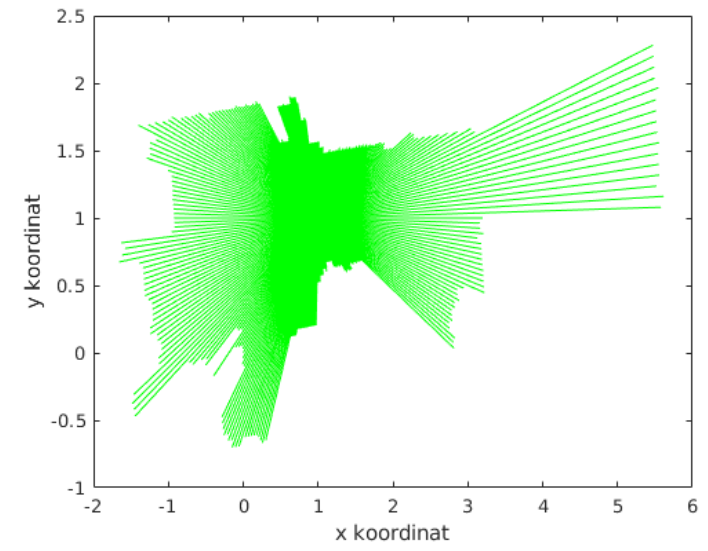

(a)

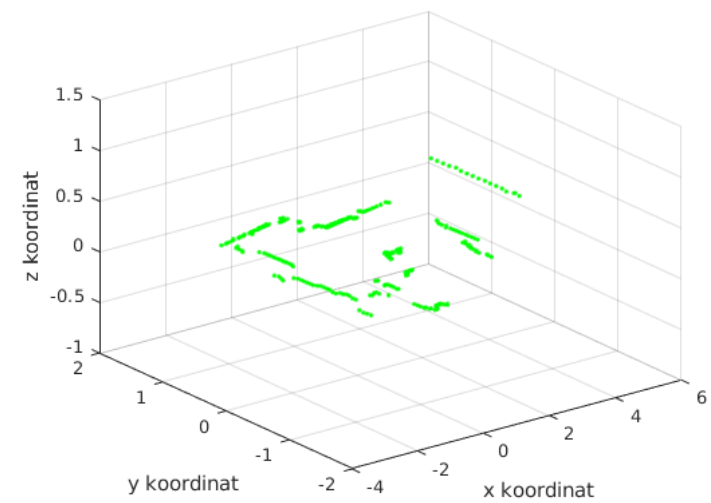

(c)

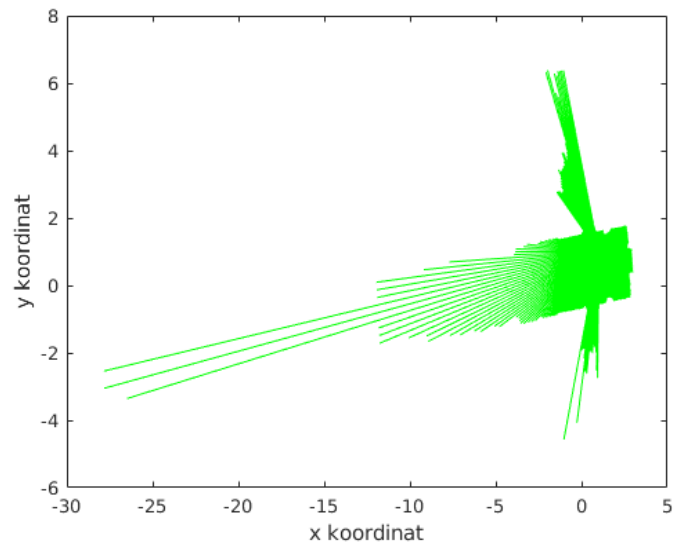

(b)

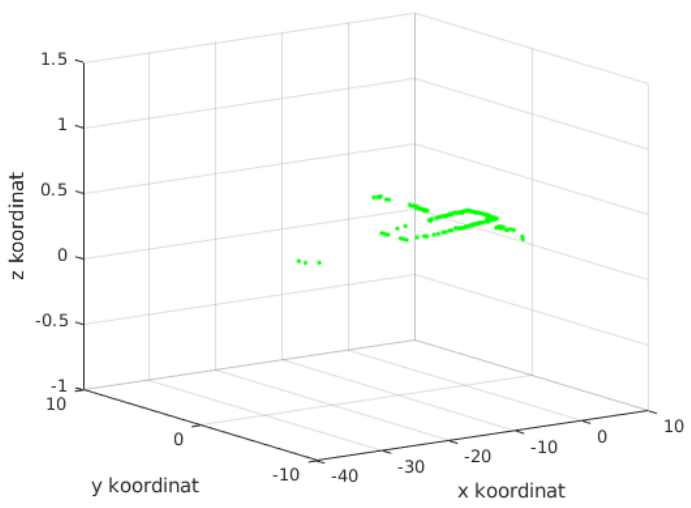

(d)

Şekil 2. Oda ve koridor konumları için elde edilen lazer taramaları ve sırası ile nokta bulutu temsilleri. (a) Oda konumuna ait lazer taraması, (b) Koridor konumuna ait lazer taraması, (c) Oda konumu için elde edilen nokta bulutu, (d) Koridor konumu için elde edilen nokta bulutu.

Nokta bulutunu doğrudan girdi olarak alan ve yerel bilgileri kullanan PointNet++ mimarisi anlamsal sınıflandırma için tercih edilmiştir. Bu mimari, iç içe geçmiş yığınlara tekrarlı olarak PointNet (ağırlıkları paylaştırılmış çok katmanlı ağlar) uygulayarak yerel özellikleri çıkartmaktadır. İlk olarak, nokta bulutu içerisinde en uzak nokta örnekleme tekniği ile yerel bölge merkezlerini 
oluşturacak $L$ adet örnekleme noktası $\left\{P_{S} \mid s=1,2, \ldots, L\right\}$ seçilmektedir. Bu merkez noktalar etrafında belirlenen yarıçap $(R)$ içerisine düşen noktalar ya da en yakın $K$ komşuluk parametresine göre bulunan noktalar $\left\{P_{n} \mid n=1,2, \ldots, K\right\}$ yerel komşuluk olarak tanımlanmış ve gruplandırılmıştır (LxKx3). Daha sonra, gruplandırılarak elde edilen bölgelerden tam bağlantılı katmanlar (MLPs Multi Layer Perceptrons) ile yerel bölgeyi tanımlayan yüksek boyutlu $(C)$ özellikler çıkarılmıştır. Son olarak, yerel bölgeyi tanımlayan $K$ adet noktaya ait özellikler $(L x K x C)$ maksimum havuzlama (Max Pool) yöntemi ile özetlenmiş ve tanımlanan tüm yerel bölgeler için özellikler ( $L x C$ ) çıkarılmıştır. Bahsedilen bu aşamalar PointNet++ mimarisinde küme özetleme modülü olarak tanıtılmış ve Şekil 3’te sadeleştirilerek gösterilmiştir.

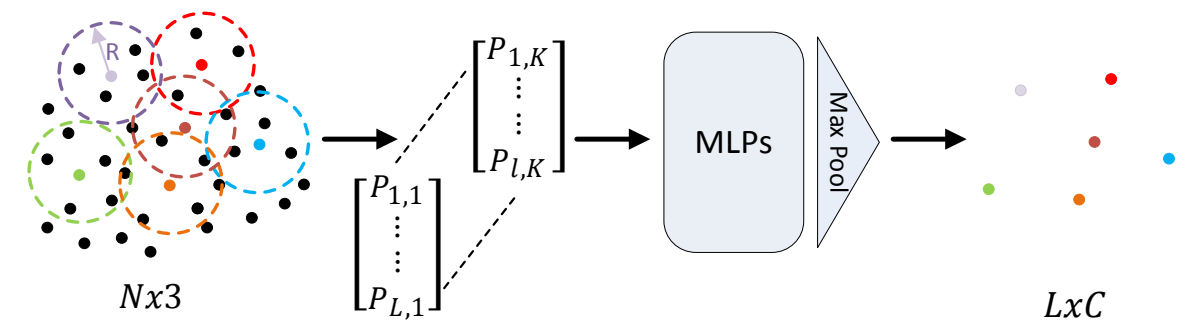

Şekil 3. PointNet++ küme özetleme modülü.

Sınıflandırma problemi için PointNet++ mimarisi Şekil 4'te verilmiştir. Lazer mesafe ölçümleri nokta bulutuna dönüştürüldükten sonra elde edilen noktalar (360x3) mimariye girdi olarak verilmektedir. Daha sonra, nokta bulutu verisine üç küme özetleme modülü ard arda uygulanmaktadır. Bu modüllerde kullanılan örnekleme noktası sayısı, komşuluk sayısı ve nöron sayıları verinin yapısı göz önüne alınarak deneysel olarak belirlenmiştir. İlk modülde, 360 nokta içerisinden 192 örnekleme noktası seçilip, her örnekleme noktasının 15 en yakın komşuluğu bulunarak yerel bölgeler oluşturulmuştur. $\mathrm{Bu}$ yerel bölgelerde sırasıyla $(64,64,128)$ nöron içeren MLP kullanılarak özellik çıkarıldıktan sonra maksimum havuzlama yöntemi ile her bölge için özellikler özetlenmiştir (192x128). Benzer şekilde, ikinci modül uygulandıktan sonra tanımlanan 48 yerel bölge için 256 özellik çıkarılmıştır. Son özetleme modülünde ise kalan tüm noktalar tek bir yerel bölge olarak değerlendirilmiş ve 256 küresel özellik öğrenilmiştir. Daha sonra, sırasıyla $(256,128,2)$ tam bağlantılı (FC - Fully Connected) katmanlardan oluşan sınıflandırma modülü ile çıkarılan küresel özellikler ve kategoriler ile arasında ilişki tanımlanmıştır. 


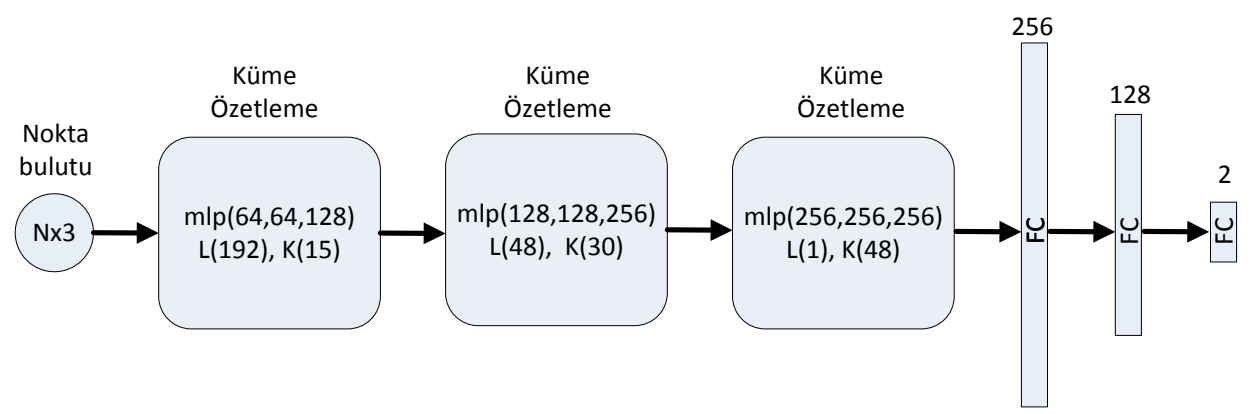

Şekil 4. PointNet++ mimarisi şematik gösterimi.

\section{Deneysel Çalışmalar}

Önerilen yöntem farklı boyutlarda oda ve koridor örnekleri içeren 4 veri kümesi ile test edilmiştir. İlk olarak, 2B lazer verileri ile robot konumlarının anlamsal sınıflandırılmasında sıklıkla kullanılan Freiburg 79 veri kümesi ele alınmıştır. Bu veri kümesinin eğitim kısmındaki her bir örnek ayrı ayrı nokta bulutuna dönüştürüldükten sonra PointNet++ mimarisine girdi olarak verilmiştir. PointNet++ mimarisi bu veriyi 250 epok, 16 grup sayısı, 0,001 öğrenme adımı ve “adam” optimizasyon yöntemi parametreleri ile eğiterek bir model üretmiştir. Ayrıca, Freiburg 79 eğitim veri kümesine veri artırımı işlemi yapılmış ve aynı süreç aynı parametreler ile bu veri kümesi için de uygulanarak ayrı bir model elde edilmiştir. Bu modeller Freiburg 52 ve ESOGÜ veri kümelerinin test edilmesinde kullanılmış; sayısal ve görsel sonuçlar elde edilmiştir. Bununla birlikte, SDB-R veri kümesi etiket bilgisine sahip olmadığı için sadece görsel sonuçlar üretilmiştir. Sayısal sonuçların değerlendirilmesinde genel sınıflandırma doğruluğu (ACC), her sınıf için sınıflandırma duyarlılığı (recall), kesinlik (precision) ve F1 ölçütü kullanılmıştır. Genel sınıflandırma doğruluğu, Eşitlik 1'de verildiği gibi doğru olarak sınıflandırılmış örnek sayısının toplam örnek sayısına oranı ile hesaplanmaktadır. Sınıflandırma duyarlılığı ise bir sınıf için doğru olarak sınıflandırılmış örnek sayısının bu sınıftaki toplam örnek sayısına oranı ile bulunmaktadır (Eşitlik 2). Eşitlik 3'te verilen kesinlik ölçütü bir sınıftaki doğru sınıflandırılmış örnek sayısının bu sınıf için toplam sınıflandırılmış örnek sayısına oranı olarak tanımlamaktadır. Eşitlik 4' de verilen F1 değeri ise sınıflandırma duyarlılı̆̆ı ve kesinliğinin harmonik ortalamasını ifade etmektedir. Deneylerin gerçekleştirildiği bilgisayar Intel Xeon işlemciye, 125 GiB hafizaya ve Ubuntu 18.04 işletim sistemine sahiptir.

$$
\begin{aligned}
& \text { Doğruluk }(A C C)=\frac{\text { Doğru Pozitif }+ \text { Doğru Negatif }}{\text { Toplam Örnek }} \\
& \text { Duyarlılık }(\text { Recall })=\frac{\text { Doğru Pozitif }}{\text { Doğru Pozitif }+ \text { Yanlış Negatif }} \\
& 236
\end{aligned}
$$




$$
\begin{gathered}
\text { Kesinlik (Precision) }=\frac{\text { Doğru Pozitif }}{\text { Doğru Pozitif }+ \text { Yanlış Pozitif }} \\
F 1=2 \frac{\text { Duyarlıllk } * \text { Kesinlik }}{\text { DDuyarllllk }+ \text { Kesinlik }}
\end{gathered}
$$

\subsection{Freiburg 79 Veri Kümesi}

Freiburg 79 veri kümesinde bulunan örnekler için robotun yönelimi rastsal olarak seçilirken robot konumları ortamın engel olmayan kısımlarında hücre boyutu 5 santimetre olan 1zgara üzerindeki köşe noktaları olarak belirlenmiştir. Her robot konumu için 360 adet lazer ölçümü bulunmaktadır. Şekil 5'te bu veri kümesinin oluşturulduğu Freiburg 79 numaralı binanın genel yapısı verilmektedir. Bu binanın boyutları 34x14,45 metredir ve bina eğitim ve test verileri için iki parçaya bölünmüştür. Şekil 5(a)'da eğitim verisinin toplandığı kısım gösterilmektedir. Eğitim verisinde 43624 oda ve 16687 koridor örneği bulunmaktadır. Test verisinde ise 50180 oda ve 15516 koridor örneği yer almakta ve Şekil 5(b)'de bu verilerin toplandı̆̆ı kısım gösterilmektedir. Ayrıca, Freiburg 79 eğitim veri kümesinde bulunan örneklere veri artırımı uygulanmıştır. Veri artırımı işleminde ilk olarak eğitim veri kümesinden rastsal örnekler seçilmiş ve seçilen örneklere rastsal olarak seçilen bir değer ile dairesel kaydırma uygulanmıştır. Daha sonra her bir lazer ölçümü için oda örnekleri 1/3,1/2,50,1/2,1/1,50, 1/0,667 ve 1/0,50 ölçekleri ile; koridor örnekleri ise 1/4, 1/3, $1 / 2,50,1 / 2,1 / 1,50,1 / 1,33,1 / 1,11,1 / 0,80$ ve 1/0,67 ölçekleri ile çoğaltılarak veri çeşitlendirilmiştir. $\mathrm{Bu}$ şekilde oluşturulan artırılmış veri kümesinde 109060 oda ve 83439 koridor örneği bulunmaktadır.

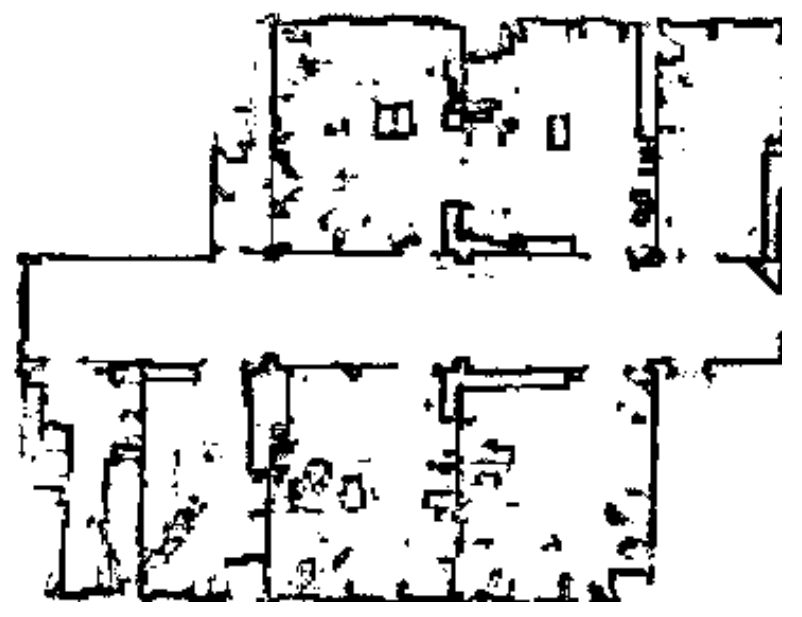

(a)

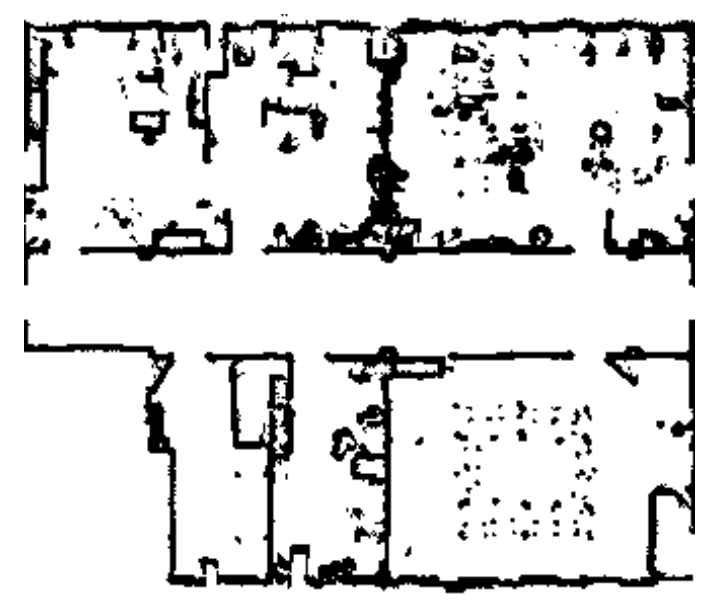

(b)

Şekil 5. Freiburg 79 numaralı binanın genel yapısı. (a) Eğitim verisinin toplandığı kısım, (b) Test verisinin toplandığı kısım. 
Tablo 1 ve Şekil 6'da Freiburg 79 test veri kümesi ile elde edilen sayısal ve görsel sonuçlar ham ve artırılmış veri için verilmiştir. Şekil 6'da mavi ve kırmızı renkler sırasıyla oda ve koridor örneklerini göstermektedir. Ayrıca, şekillerde yer alan sarı elipsler ise hatalı sınıflandırma yapılan örneklere dikkat çekmek için kullanılmıştır. Şekil 6 ve Tablo 1 birlikte incelendiğinde ham ve artırılmış veri için PointNet++ mimarisinin oda ve koridor sınıflarına ait örneklerin çok büyük bir kısmını doğru bir şekilde sınıflandırdığı görülmektedir. Aynı zamanda, yanlış sınıflandırılan örnek sayısının da oldukça düşük olduğu kesinlik sonuçları ile gözlemlenmiştir. Ham ve artırılmış veri kendi aralarında karşılaştırıldığında ise ham veri ile elde edilen sonuçların artırılmış veri ile elde edilen sonuçlara göre bir miktar daha yüksek olduğu görülmektedir. Bu beklenen bir sonuçtur çünkü artırılmış veri içerisinde çok çeşitli ölçeklerde veriler bulunmakta ve bu verilerin bazılarında ölçeklendirmeden kaynaklı olarak oda ve koridor örnekleri birbirlerine oldukça benzemektedir. Bu duruma bazı örnekler Şekil 6(b)'de sarı elipsler ile gösterilmiştir. Diğer yandan, ham veri ile elde edilen model, aynı ölçekte bir veri ile test edildiği için hemen hemen hiç hata yapmadan sınıflandırma yapabilmektedir (Şekil 6(a)).

Tablo 1. Freiburg 79 veri kümesi sayısal sonuçları

\begin{tabular}{|c|c|c|c|c|c|c|c|}
\hline \multirow{2}{*}{ Veri Türü Ölçüt } & \multirow{2}{*}{ ACC } & \multicolumn{2}{|c|}{ Duyarlılık } & \multicolumn{2}{|c|}{ Kesinlik } & \multicolumn{2}{|c|}{ F1 Skoru } \\
\hline & & Oda & Koridor & Oda & Koridor & Oda & Koridor \\
\hline Ham & 99.96 & 99.98 & 99.87 & 99.96 & 99.94 & 99.97 & 99.90 \\
\hline Artırılmış & 99.58 & 99.79 & 98.91 & 99.66 & 99.31 & 99.73 & 99.11 \\
\hline
\end{tabular}

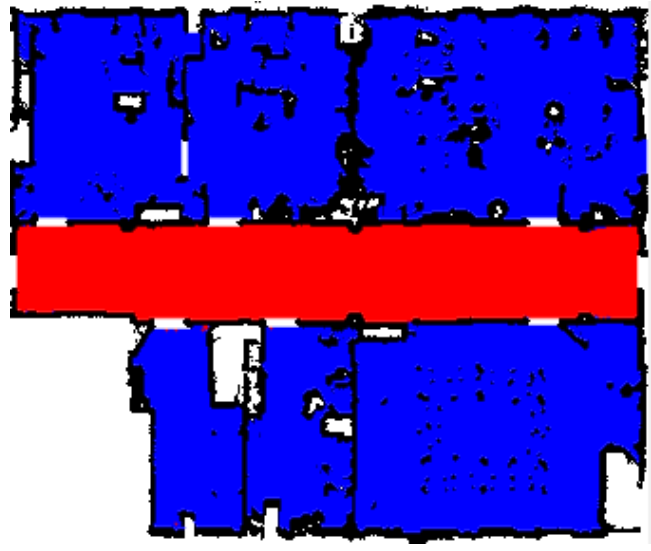

(a)

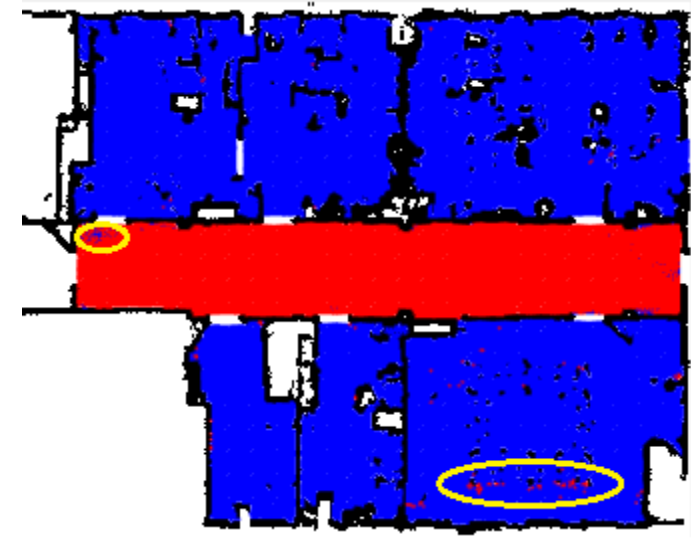

(b)

Şekil 6. Freiburg 79 veri kümesi görsel sonuçları. (a) Ham veri sonuçları, (b) Artırılmış veri sonuçları. 


\subsection{Freiburg 52 Veri Kümesi}

Önerilen yöntemin genelleştirme kabiliyetini ölçmek için ilk olarak Freiburg 52 veri kümesi kullanılmıştır. Bu veri kümesinin oluşturulduğu Freiburg 52 nolu binanın genel yapısı Şekil 7'de gösterilmektedir. Şekilde gösterilen binanın boyutları 27,15x14,60 metredir ve Freiburg 79 nolu bina ile karşılaştırıldığında hemen hemen aynı genişliğe sahip olsa da uzunluğu yaklaşık olarak \%20 oranında daha kısadır. Bu veri kümesindeki örnekler için Freiburg 79 veri kümesinde olduğu gibi robotun yönelimi rastsal olarak seçilmiş ve 5 santimetre aralıklarla belirlenen robot konumlarından 360 adet lazer ölçümü alınmıştır. Veri kümesi eğitim ve test olmak üzere iki kısma ayrılmıştır. Ancak, bu çalışmada bu veri kümesinin sadece test kısmı Freiburg 79 veri kümesi ile eğitilen PointNet++ modellerinin performansını ölçmek için kullanılmıştır. Freiburg 52 veri kümesinin test kısmında 32214 oda ve 6093 koridor örneği bulunmaktadır.

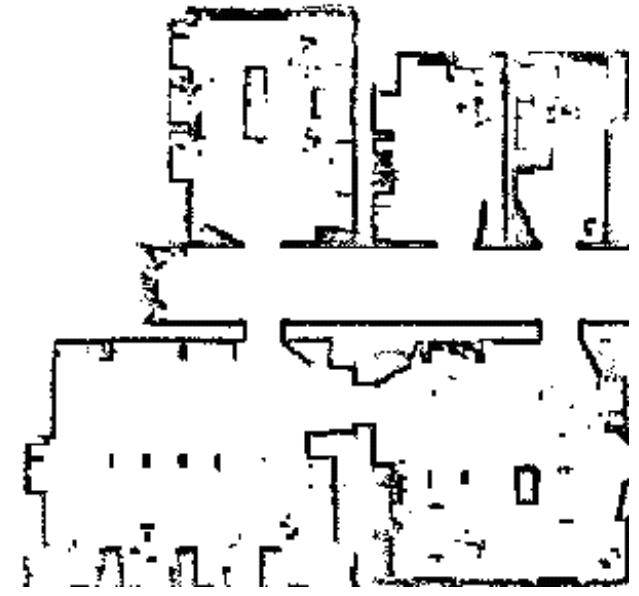

(a)

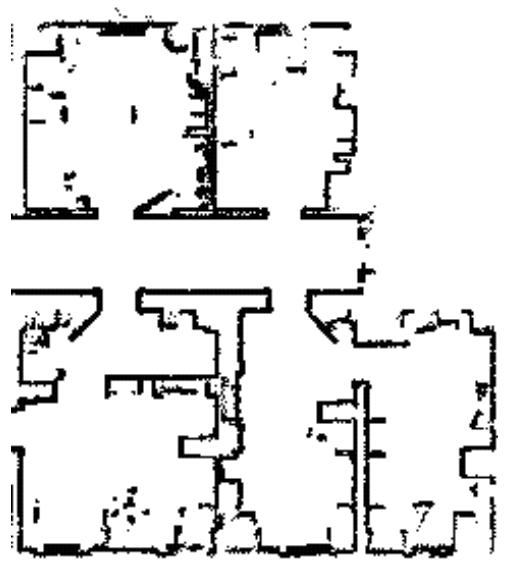

(b)

Şekil 7. Freiburg 52 numaralı binanın genel yapısı. (a) Eğitim verisinin toplandığı kısım, (b) Test verisinin toplandı̆̆ 1 kısım

Freiburg 52 test veri kümesi ile elde edilen sayısal ve görsel sonuçlar ham ve artırılmış veri için sırasıyla Tablo 2 ve Şekil 8'de verilmiştir. Görsel ve sayısal sonuçlar birlikte incelendiğinde Freiburg 79 eğitim veri kümesi ile eğitilen modellerin Freiburg 52 test veri kümesinde oldukça başarılı bir şekilde sınıflandırma yaptıkları anlaşılmaktadır. Bunun temel sebeplerinden birisi bu iki veri kümesinin oluşturulduğu ortamların boyutlarının birbirlerine önemli ölçüde benzer olmasıdır. $\mathrm{Bu}$ durumda, Freiburg 52 test veri kümesindeki örnekler boyut olarak Freiburg 79 eğitim veri kümesindeki örneklere benzemekte ve PointNet++ eğitimde öğrendiği örneklere benzer örnekleri 
test aşamasında da gördüğünden başarılı bir şekilde sınıflandırmaktadır. İki veri türü kendi aralarında kıyaslandığında ise sayısal sonuçların birbirlerine çok yakın olduğu görülse dahi PointNet++ mimarisinin farklı veri türleri için farklı durumlarda yanlış sınıflandırmalar yaptı̆̆ görsel sonuçlar ile gözlemlenmiştir. Ham veriyi ele aldığımızda hatalı sınıflandırmaların genellikle koridor konumlarında olduğu görülmektedir. Bunun sebebi, Freiburg 79 nolu binanın eğitim kısmında yer alan koridorun, Freiburg 52 nolu binanın test kısmında yer alan koridordan yaklaşık olarak \%40 daha uzun olmasıdır. Dolayısıyla, test veri kümesindeki bazı örnekler için eğitim kümesinde uygun örnek bulunmamakta ve bu örnekler hatalı sınıflandırılmaktadır. Şekil 8(a)'da sarı elipsler ile gösterilen hatalı koridor konumları bu duruma örnek olarak gösterilebilir. Artırılmış veri sonuçları incelendiğinde hatalı sınıflandırılan örneklerin genellikle odaların uç noktalarında yer aldığı ve bu noktalardaki lazer ölçümlerinde aynı koridor örneklerinde olduğu gibi uzun 1şınlar olabileceği düşünülmektedir (Şekil 8(b)).

Tablo 2. Freiburg 52 veri kümesi sayısal sonuçları

\begin{tabular}{lccccccc}
\hline \multirow{2}{*}{ Ölçüit } & \multirow{2}{*}{ ACC } & \multicolumn{2}{c}{ Duyarlılık } & \multicolumn{2}{c}{ Kesinlik } & \multicolumn{2}{c}{ F1 Skoru } \\
Veri Türü & & Oda & Koridor & Oda & Koridor & Oda & Koridor \\
\hline Ham & 99.92 & 99.96 & 99.72 & 99.95 & 99.79 & 99.95 & 99.76 \\
Artırılmış & 99.89 & 99.92 & 99.76 & 99.95 & 99.58 & 99.94 & 99.66 \\
\hline
\end{tabular}

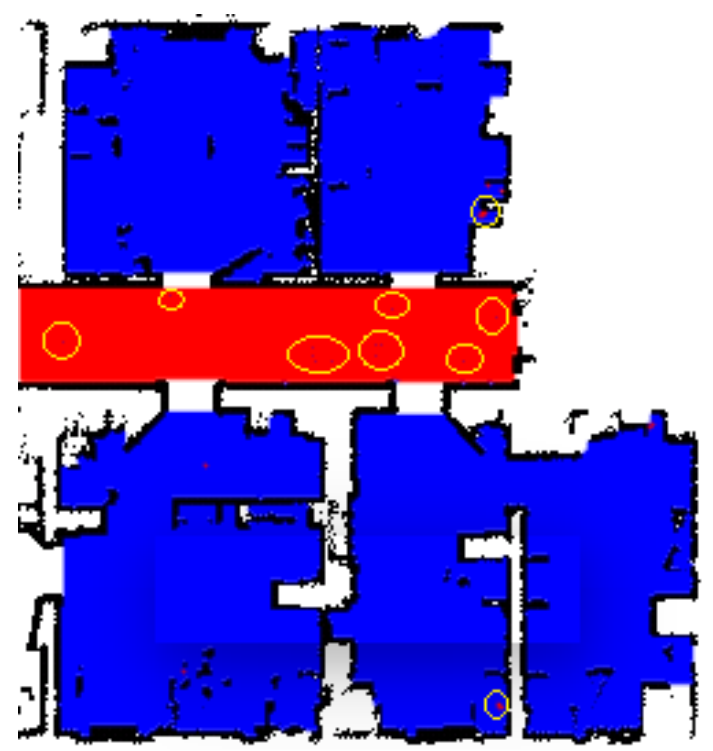

(a)

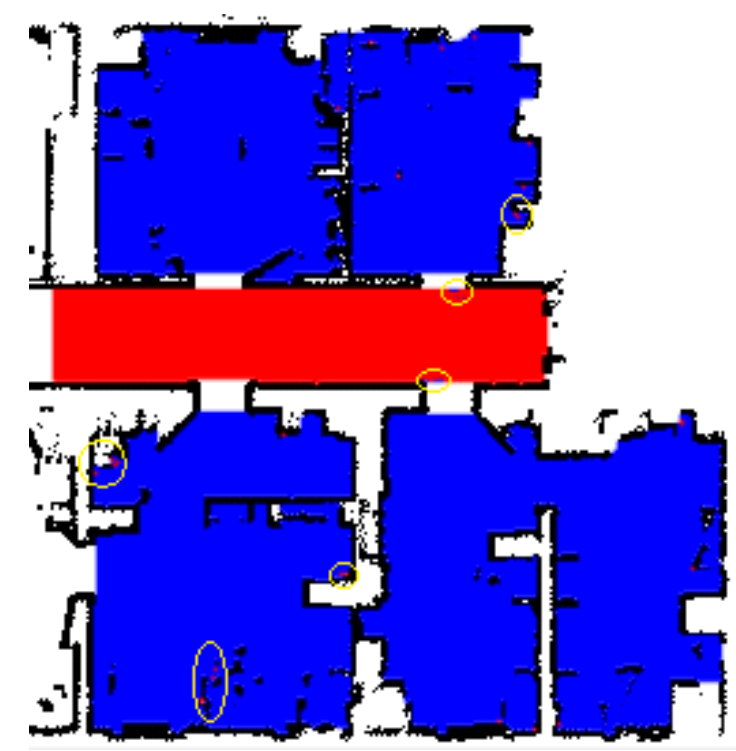

(b)

Şekil 8. Freiburg 52 veri kümesi görsel sonuçları. (a) Ham veri sonuçları, (b) Artırılmış veri sonuçları. 


\subsection{ESOGÜ Veri Kümesi}

Freiburg 79 ve Freiburg 52 veri kümeleri ile başarılı sonuçlar elde edildikten sonra aslında bu veri kümelerinin birbirlerine oldukça benzediği ve gerçeklenen yöntemin başarısı hakkında analiz yapabilmek için tamamen farklı bir ortamda testler yapılması gerekliliği ortaya çıkmıştır. Bu testler için Eskişehir Osmangazi Üniversitesi Elektrik-Elektronik Mühendisliği Bölümü Laboratuvar binası uygun görülmüştür. Bu binanın boyutları 48x15 metredir ve genel yapısı Şekil 9(a)'da verilmiştir. $\mathrm{Bu}$ şekil dikkatli incelendiğinde ESOGÜ Laboratuvar binasındaki oda ve koridor boyutlarının Freiburg 79 ve Freiburg 52 nolu binalardaki oda ve koridor boyutlarından oldukça farklı olduğu gözlemlenmektedir. ESOGÜ veri kümesini oluşturmak amacıyla laboratuvar binası Gazebo (2020), benzetim ortamında modellenmiştir. Daha sonra bir Pioneer P3-AT (2020) gezgin robotun üzerine 2 adet SICK LMS 200 lazer mesafe ölçer yerleştirilerek benzetim ortamında yer alması sağlanmıştır. Şekil 9(b)'de ESOGÜ Laboratuvar binasının Gazebo benzetim ortamında oluşturulan modeli verilmektedir. Şekilde robot siyah olarak gözükmekte ve etrafında mavi renklerle lazer ışınları bulunmaktadır. Robot İşletim Sistemi (Robot Operating System - ROS (2020)) robotu kontrol etmek için kullanılmıştır. Robot kendisine verilen rastsal rotaları izlerken aynı zamanda da 360 adet lazer ölçümü ile robotun konum ve yönelimini 1 saniye aralıklarla kaydederek ESOGÜ veri kümesini oluşturmuştur. Elde edilen veri kümesi etiketleme işleminden geçirildikten sonra 15353 oda ve 20691 koridor örneğine sahip olduğu görülmüştür. Veri kümesindeki bütün örnekler test için kullanılmıştır.

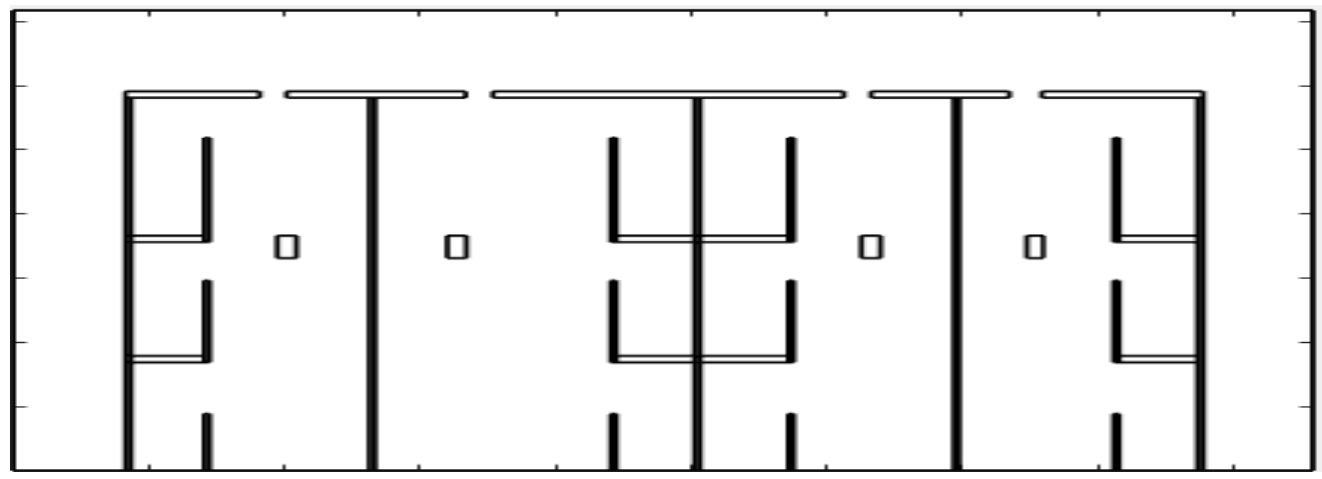

(a) 


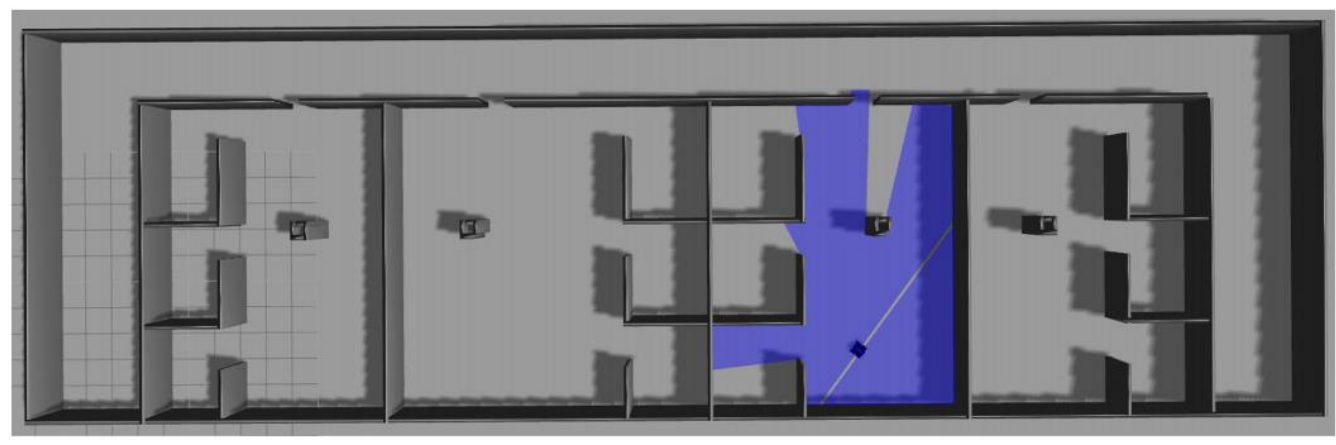

(b)

Şekil 9. (a) Eskişehir Osmangazi Üniversitesi Elektrik-Elektronik Mühendisliği Laboratuvar binasının genel yapıs1, (b) Gazebo benzetim ortamında oluşturulan modeli.

ESOGÜ veri kümesi ile elde edilen sayısal ve görsel sonuçlar ham ve artırılmış veri için sırasıyla Tablo 3 ve Şekil 10'da verilmiştir. İlk olarak, ham veri için elde edilen sayısal ve görsel sonuçlar birlikte ele alınmıştır. Şekil 10(a)'da görüldüğü üzere veri kümesindeki hemen hemen bütün noktalar koridor olarak sınıflandırılmıştır. Bu açıkçası beklenen bir sonuçtur çünkü ESOGÜ veri kümesindeki 4 büyük odanın boyutları yaklaşık olarak Freiburg 79 binasının eğitim kısmında bulunan odaların iki katı kadardır. Bu durumda, PointNet++ mimarisi ESOGÜ veri kümesindeki oda örneklerini Freiburg 79 eğitim veri kümesindeki oda örneklerinden daha ziyade koridor örneklerine benzetmekte ve yanlış sınıflandırma yapmaktadır. Sonuç olarak, ham veri kullanılarak eğitilen PointNet++ mimarisinin odanın izotropik ve koridorun dar uzun karakteristiklerini öğrenmek yerine sadece oda ve koridorların boyutlarını öğrendiği ve bunları kullanarak sınıflandırma yaptığı anlaşılmaktadır.

Tablo 3. ESOGÜ veri kümesi sayısal sonuçları

\begin{tabular}{lccccccc}
\hline \multirow{2}{*}{ Ölçüt } & \multirow{2}{*}{ ACC } & \multicolumn{2}{c}{ Duyarlılık } & \multicolumn{2}{c}{ Kesinlik } & \multicolumn{2}{c}{ F1 Skoru } \\
Veri Türü & & Oda & Koridor & Oda & Koridor & Oda & Koridor \\
\hline Ham & 59.12 & 4.01 & 100 & 100 & 58.41 & 7.73 & 73.74 \\
Artırılmış & 98.03 & 98.90 & 97.39 & 96.57 & 99.17 & 97.72 & 98.27 \\
\hline
\end{tabular}




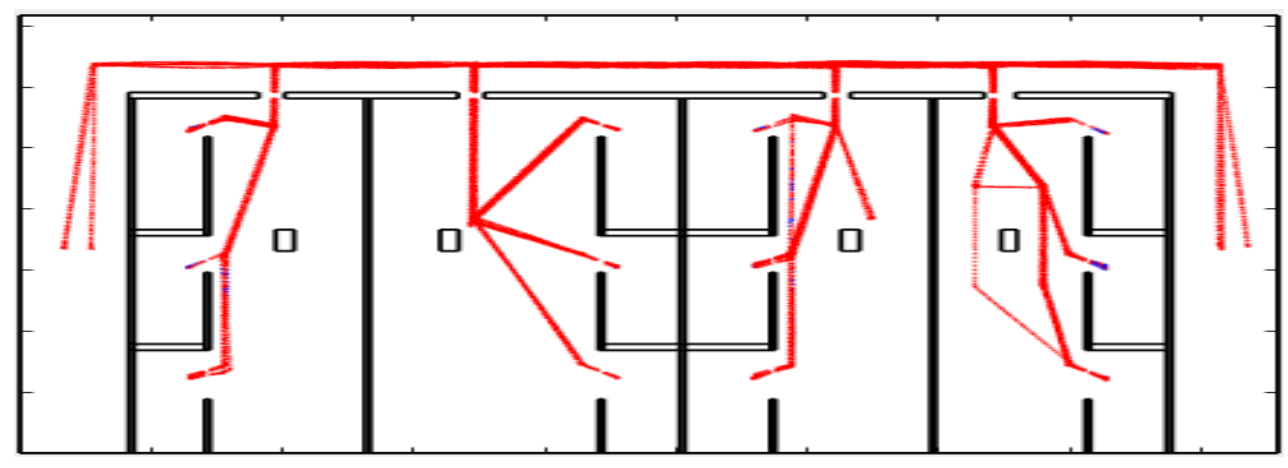

(a)

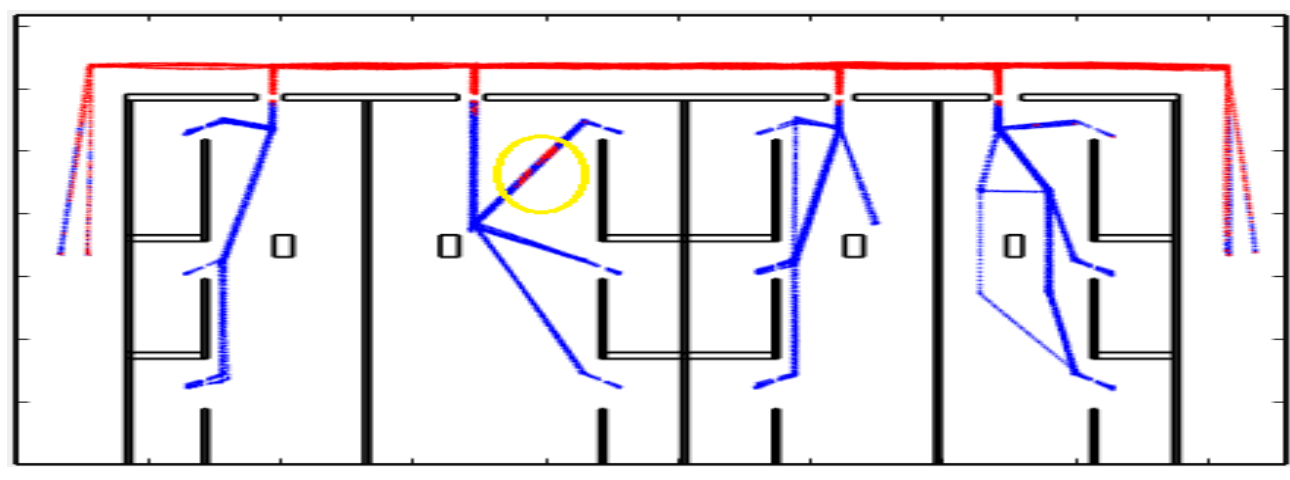

(b)

Şekil 10. ESOGÜ veri kümesi görsel sonuçları. (a) Ham veri sonuçları, (b) Artırılmış veri sonuçları.

Artırılmış veri içerisinde oda ve koridorlar için çeşitli ölçeklerde örnekler bulunmaktadır. $\mathrm{Bu}$ durum, aynı boyutlara sahip oda ve koridor örneklerinin de eğitim veri kümesinde olmasını ve PointNet++ mimarisinin oda ve koridor sınıflarını belirlemek için sadece boyutları değil aynı zamanda bu sınıfların karakteristik özelliklerini de öğrenmesini sağlamaktadır. Tablo 3 ve Şekil 10(b) birlikte incelendiğinde oda sınıfına ait örneklerin şekilde sarı elips ile gösterilen bölge dışında hemen hemen tamamının doğru şekilde sınıflandırıldığg görülmektedir. Bununla birlikte, özellikle ortamın sağında ve solunda yer alan ve büyük odalara çok benzeyen koridorlarda PointNet++ mimarisi koridor ve oda sınıflarını birbirine karıştırmaktadır. Bu bölgelerde, iki sınıf arasındaki farklar gittikçe azaldığı için ortamın bu kısımlarında yer alan örneklerde PointNet++ mimarisinin hatalı sınıflandırma yapması kabul edilebilir bir sonuçtur.

\subsection{SDR-B Veri Kümesi}

SDR-B veri kümesinde (Mozos, 2020) yer alan örnekler Amerika Birleşik Devletleri’nin Virginia eyaletinde bulunan boş bir binadan toplanmıştır. Bu binanın boyutları 16,15x14,35 
metredir ve Şekil 11'de bu binanın genel yapısı gösterilmektedir. Freiburg 79, Freiburg 52 ve ESOGÜ binalarından oldukça farklı olan bu yapı, çok dar koridorlara ve boyutları diğer binalar ile karşılaştırıldığında oldukça küçük odalara sahiptir. SDR-B binasındaki koridorlar Freiburg 79 ve Freiburg 52 binalarındaki koridorlardan yaklaşık olarak iki katı daha uzundur; ancak ESOGÜ laboratuvar binasındaki koridorların üçte biri uzunluğundadır. Diğer yandan, bu binadaki odaların boyutları Freiburg 79 ve ESOGÜ binalarındaki odaların boyutlarının sırasıyla yaklaşık olarak üçte biri ve altıda biri kadardır. Bu veri kümesi sadece test için tasarlandığı için etiket bilgisi bulunmamaktadır. Dolayısıyla sadece görsel sonuçlar verilmiştir.

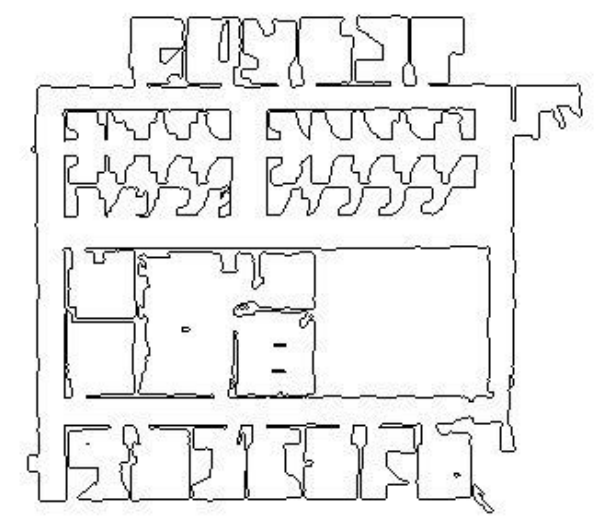

Şekil 11. SDR-B binasının genel yapısı.

SDR-B veri kümesi ile elde edilen görsel sonuçlar ham ve artırılmış veri için Şekil 12'de verilmiştir. Şekil 12(a)'da görüldüğü üzere veri kümesindeki hemen hemen bütün noktalar oda olarak sınıflandırılmıştır. Bu beklenen bir durumdur çünkü bu veri kümesinde yer alan koridor örnekleri için bazı lazer ölçümleri, Freiburg 79 eğitim veri kümesindeki koridor örneklerinde bulunan lazer ölçümlerinin yaklaşık olarak iki katı kadardır. Bu durumda, PointNet++ mimarisi SDR-B veri kümesindeki koridor örneklerini Freiburg 79 veri kümesindeki koridor örneklerinden daha ziyade oda örneklerine benzetmektedir. Sonuç olarak, ham veri ile elde edilen model için ESOGÜ verisi ile benzer bir durum SDR-B veri kümesinde de ortaya çıkmıştır. Diğer yandan, artırılmış veri ile eğitilen model koridorların büyük bir kısmını doğru şekilde sınıflandırmayı başarmıştır. 


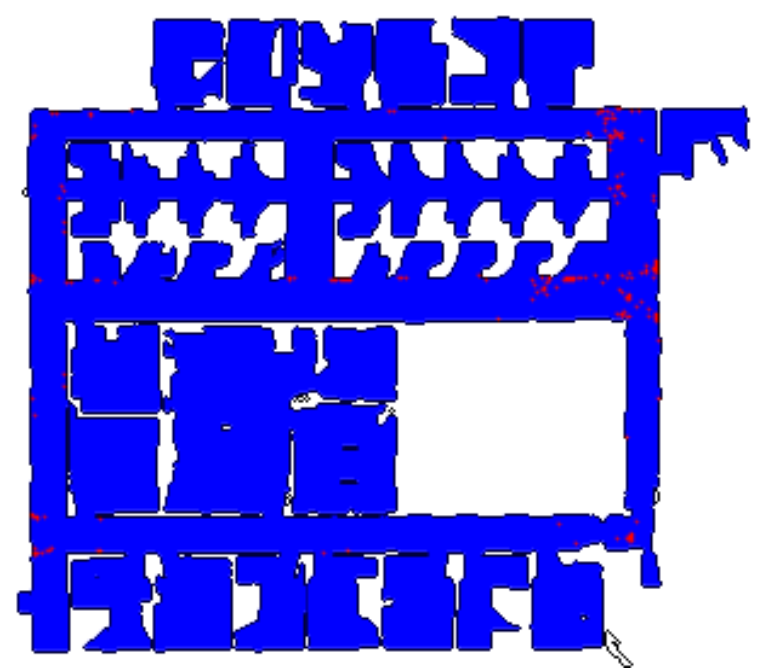

(a)

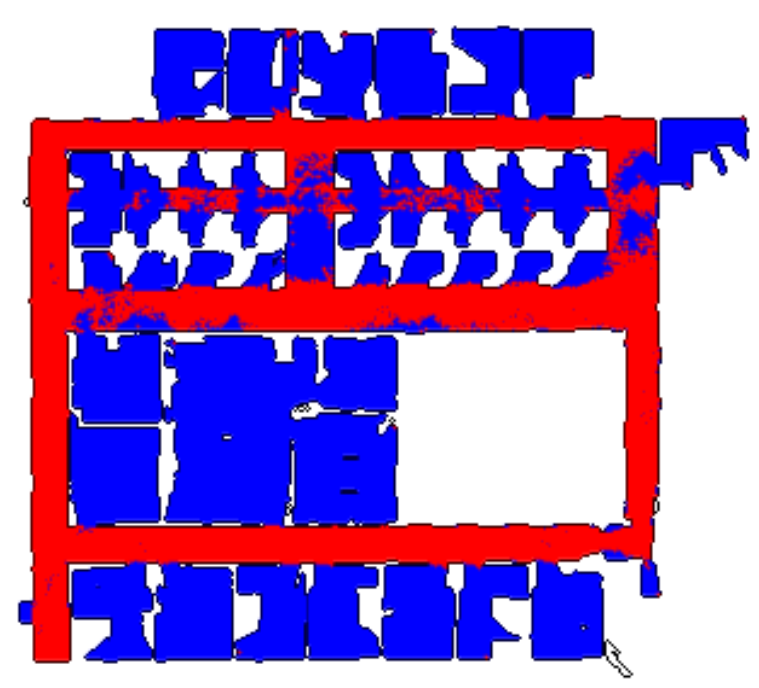

(b)

Şekil 12. SDR-B veri kümesi görsel sonuçları. (a) Ham veri sonuçları, (b) Artırılmış veri sonuçları.

\section{Sonuçlar}

Bu çalışmada, robot konumlarının anlamsal sınıfına karar verebilmek için 2B lazer verileri kullanılmıştır. Daha önceki çalışmalarda kümeleme, çizge, denetimli ve denetimsiz makine öğrenmesi yöntemleri bu problemin çözümünde kullanılmıştır. Gerçeklenen PointNet++ mimarisi ile nokta bulutu verisi için geliştirilen derin öğrenme tekniklerinin sunduğu potansiyeli 2B lazer verileri için gözlemlemek amaçlanmıştır. Ayrıca, PointNet++ mimarisinin oda sınıfının izotropik ve koridor sınıfının ise dar ve uzun karakteristiğini öğrenmesi için veri artırımı yapılmıştır. Freiburg 79, Freiburg 52, ESOGÜ ve SDR-B gibi çok farklı boyutlarda oda ve koridorlardan elde edilmiş örnekler bulunduran 4 veri kümesi kullanılarak gerçeklenen yöntemin ve veri artırımının etkileri gözlemlenmiştir. Test sonuçları, veri artırımı ile bahsedilen bütün ortamlarda başarılı bir şekilde oda ve koridor sınıflarının tespit edildiğini göstermiştir. Bu çalışma, nokta bulutu için geliştirilen derin öğrenme tekniklerinin 2B lazer verilerine uygulanabileceğini göstermiştir. Ayrıca umut verici sonuçlar içerdiği için gelecek çalışmalara da esin kaynağı olması umulmaktadır.

\section{Kaynaklar}

Gazebo Robot Simulation (2020). Open source robotics foundation (OSRF). http://gazebosim.org/. Erişim: 25.06.2020.

Goeddel, R. ve Olsom, E. (2016). Learning semantic place labels from occupancy grids using CNNs. IEEE/RSJ International Conference on Intelligent Robots and Systems, s: 3999-4004. 
Turgut, K., Kaleci, B., Uluslararası Doğu Anadolu Fen Mühendislik ve Tasarım Dergisi / International Journal of Eastern Anatolia Science Engineering and Design (IJEASED)

(2020) 2(2):229-246

Guo, J. Y., Wang, H., Hu, Q., Liu, H., Liu. L ve Bennamoun, M. (2019). Deep learning for 3D point clouds: A survey. arXiv: 1912.1203.

Kaleci, B., Şenler, Ç.M., Dutağac1, H. ve Parlaktuna, O. (2020). Semantic classification of mobile robot locations through 2D laser scans. Intel Serv Robotics, Cilt:13, s:63-85.

Liao, Y., Kodagoda, S., Wang, Y., Shi, L. ve Liu, Y. (2017). Place Classification With a Graph Regularized Deep Neural Network. IEEE Transactions on Cognitive and Developmental Systems, Cilt:9, No:4, s:304-315.

Maturana, D. ve Scherer, S. (2015). VoxNet: A 3D Convolutional Neural Network for real-time object recognition. IEEE/RSJ International Conference on Intelligent Robots and Systems (IROS), s:. 922928, doi: 10.1109/IROS.2015.7353481.

Mozos, O. M. (2010). Semantic Labeling of Places with Mobile Robots. Springer Tracts in Advanced Robotics (STAR), Cilt:61.

Mozos, O. M. (2020). Semantic Place Labeling Datasets. http://www2.informatik.unifreiburg.de/ omartine/place data sets.html, Erișim: 25.06.2020.

Mozos, O. M. ve Burgard, W. (2006). Supervised learning of topological maps using semantic information extracted from range data. IEEE/RSJ international conference on intelligent robots and systems, s:2772-2777.

Mozos, O. M., Stachniss, C. ve Burgard, W. (2005). Supervised learning of places from range data using adaboost. IEEE International Conference on Robotics and Automation, s:1730-1735.

Nikdel , P. ve Vaughan, R. (2019). Recognizing and Tracking High-Level, Human-Meaningful Navigation Features of Occupancy Grid Maps. ArXiv abs/1903.03669.

Pioner P3-AT Mobile Robot (2020). https://www.generationrobots.com/media/Pioneer3AT-P3AT-RevAdatasheet.pdf, Erişim: 25.06.2020.

Premebida C., Faria D. R., Souza F. A. ve Nunes U. (2015). Applying probabilistic mixture models to semantic place classification in mobile robotics. IEEE/RSJ international conference on intelligent robots and systems (IROS), s:4265-4270.

Qi, C. R., Su, H., Mo, K. ve Guibas L. J. (2016). PointNet: Deep Learning on Point Sets for 3D Classification and Segmentation. arXiv preprint arXiv:1612.00593.

Qi, C. R., Yi, 1. E., Su, H., Mo, K. ve Guibas L. J. (2017). PointNet++: Deep Hierarchical Feature Learning on Point Sets in a Metric Space. arXiv preprint arXiv:1706.02413.

Robot Operating System (2020). Open source robotics foundation (OSRF). http://ros.org/. Erişim: 25.06.2020.

Shi, L. ve Kodagoda, S. (2013). Towards generalization of semisupervised place classification over generalized Voronoi graph, Robotics and Autonomous Systems. Cilt:61, No:8, s:785-796.

Shi L., Kodagoda S. ve Dissanayake G. (2010). Laser range data based semantic labeling of places. IEEE/RSJ international conference on intelligent robots and systems, s:5941-5946.

Soares, S. ve Araújo, R. (2014). Semantic place labeling using a probabilistic decision list of adaboost classifiers. Int. J. Comput. Inf. Syst. Ind. Manag. Appl., Cilt:6, s:548-559.

Sousa P., Araújo R. ve Nunes U. (2007). Real-time labeling of places using support vector machines. IEEE international symposium on industrial electronics, s:2022-2027.

Su, H., Maji, S, Kalogerakis, E. ve Learned-Miller, E. (2015). Multi-view Convolutional Neural Networks for 3D Shape Recognition. Proceedings of ICCV. 